\title{
Mechanical and Physical Properties of Polyester Reinforced Glass Fibre/Orange Peel Particulate Hybrid Composite
}

\author{
Rabiu Onoruoiza Mamman ${ }^{1 *}$, Aliyu Mohammed Ramalan ${ }^{2}$ \\ ${ }^{1}$ Department of Mechanical Engineering, Federal University of Technology Minna, 920211, Nigeria \\ ${ }^{2}$ Department of Metallurgical and Materials Engineering, Ahmadu Bello University Zaria, 810211, Nigeria
}

${ }^{*}$ Corresponding Author email: rabiumamman87@gmail.com

Article Histary

Received: 19 August 2019

Revised: 18 September 2019

Accepted: 04 October 2019

Published: 20 October 2019

Student(s)

- Rabiu Onoruoiza Mamman

Academic Year: 2015-16

Course Level: Master

Course Name: Mechanical Engineering (Industrial and Production)

Course year: Final Year

$\operatorname{Mentor}(s)$

- Aliyu Mohammed Ramalan

\section{ABSTRACT}

This study was focused on the development of hybrid composed using orange peel particulate dispersed in an unsaturated polyester resin reinforced with chopped strands of E-glass fibers. Orange peel particulate of about $350 \mu \mathrm{m}$ sieve size, of varying weight percentage (3, 6, 9,12 and 15) wt.\% and E-glass fiber of constant weight percentage $25.1 \mathrm{wt} \%$ was used as reinforcements in a polyester matrix. The effect of the orange peel particulate on the physical and mechanical properties of the resulting composite such as tensile strength, bending strength, impact strength and hardness strength was investigated. The results showed remarkable improvement in mechanical properties with increase in percentage of particulate reinforcement. Tensile strength varies from 50.0 to $62.6 \mathrm{MPa}$, Hardness values varies between 28.6 and $40.8 \mathrm{HRB}$, Impact energy at room temperature, varies between 5.0 to 7.4 Joules, as a function of fiber weight fractions and the flexural strength varies from 74.0 to $85.2 \mathrm{MPa}$. The best mechanical properties were obtained at $15 \mathrm{Wt} . \%$ particulate reinforcements. The results of the physical tests show that the water absorption increases as the weight percentage of the particulate reinforcement increases and the same condition also holds for the density.

Keywords: Glass fibre; polyester resin, particulate reinforcement, orange peel, physical and mechanical properties.

\section{Introduction}

Recent advancement in composite technology have mandated the need to explore varieties of materials as reinforcements with the intention of increasing the mechanical, physical, aesthetics and thermal properties of the resulting composite formation. Also taking into cognizance, environmental concerns, most studies within the realm of composite material development, are now focused on the utilization of environmentally friendly materials especially the bio-based materials in composite development [1][2][3][4]. The reinforcements incorporated in composite materials are usually the load carrying components embedded in a matrix material. The reinforcement usually provides the properties that are absent in the matrix such as strength 
and rigidity amongst others, while the matrix usually maintains the position and orientations of the reinforcements. The matrix materials are normally polymeric based such as the synthetic polymers among them which includes; polyester, epoxy, polyurethane, polyamides and polyethylene. Matrix materials can also be of natural origin such as; chitosan, pectin, latex and others.

These reinforcements materials can either be particulate [5] or fibrous [6]. Fibrous reinforcements are normally dispersed in a thermosetting resin matrix with a view of increasing stiffness and strength. The stiffness of fiber reinforced plastics is a function of the properties of the fiber properties as well as the quantity of the fiber added hence, for a composite made of uniaxially aligned fibers, properties in the direction of the fibers may be estimated from the properties of the components by law of mixture [7]. Incorporation of two or more reinforcements into a single matrix is referred to as hybridization and the resulting material is referred to as a hybrid composite. There is increasing interest in hybrid composites because this material offers a range of properties, such as fracture toughness and impact resistance, which cannot be obtained with a single layered type of reinforcement and the same time materials cost is reduced by carefully selecting materials [8]. Hybrid effect is the attribute of composites of hybrid construction with properties better than the sum of the components.

A lot of work has been done to develop and as well, characterize the properties of dual and hybrid composites using different varieties of matrix and reinforcements materials however, an extensive review of such works is not within the scope of this paper, but some worthy mentions will be presented. Kumar et al., [9] investigated the thermal performance of Acrylonitrile Butadiene Styrene (ABS) copolymer blended with Polytetrafluroethylene (PTFE) and injection moulding process was employed during the composite fabrication. The outcome of the study showed that the addition of $10 \%$ and $20 \%$ PTFE to the ABS improve the coefficient of linear expansion of the resulting composite when compared to the pure ABS. Nabinejad et al., [10] developed a hybrid composite based on multi-walled carbon nanotubes and oil palm shell powder, both embedded in an unsaturated polyester resin. The particulate reinforcements were dispersed in the matrix using ultrasonic and solvent mixing methods. Using four different solvents namely; ethanol, methanol, acetone and styrene, the result of the study showed that the composite with the styrene solvent exhibited best mechanical and thermal properties compared to other solvents. Usman et al., [1] investigated the effect of groundnut shell powder on the mechanical and biodegradability of recycled polyethylene. Using a treated and untreated groundnut shell powder as a reinforcement for recycled polyethylene to produce a groundnut shell powder-recycled polyethylene composite. Results from the mechanical test showed that the treated samples showed better mechanical properties compared to the untreated samples while results from water absorption showed that the untreated groundnut shell powder showed higher water absorption compared to the treated sample. Other works include; Zhang et al., [11] developed a poly(methyl-methacrylate) decorated single wall epoxy/carbon-nanotube composite, Uygunoğlu et al., [12] investigated the wear and friction properties of epoxy reinforced boron wastes composites, FonsecaFerreira et al., [13] carried out a thermogravimetric characterization of polyester matrix reinforced eucalyptus fibers, Jones et al., [14] investigated the role of microstructure in ultralow wear fluoropolymer composites, Yuan et al., [15] investigated the tribological properties of polytetrafluoroethylene (PTFE) composites filled with polyetheretherketone (PEEK) and nano- $\mathrm{Al}_{2} \mathrm{O}_{3}$ particles were studied using a block-on-ring wear tester.

Orange (Citrus Sinensis) is a common commercial crop mostly grown in the North-Central part of Nigeria. According to the 2007 Food and Agricultural Organization's report, Nigeria rank $9^{\text {th }}$ citrus producing country with a total production capacity of 3,325000 tonnes [16], and as a result of the current diversification of the Nigerian economy with agriculture as a core focus, there is an expected increase in citrus production. Orange peel is a waste product of orange and this material is lignocellulosic which can be used either as a fiber or particulate reinforcement in composite development. However, there is limited study on its application within this realm, and this is the gap this study seeks to explore. With the continuous rise in orange peel waste in Nigeria, this study is aimed at utilizing orange peel particulate in as a reinforcement in a fiber reinforced polymer composite with the hope of improving the mechanical and physical properties of the resulting hybrid formation. 


\section{Materials and Methods}

\subsection{Materials}

Unsaturated polyester resin was procured Chibest Chemicals Kaduna Nigeria and used as matrix material. Cobalt Napthanate and Methyl-Ethyl-Ketone Peroxide was procured from the same company and used as curing agents and accelerators. Chopped strands of E-glass fibers were procured from the polymer department of Science Equipment Development Institute of Nigeria and employed as a reinforcement in the polymer matrix. Orange peel were locally sourced from major retailers in Nigeria, washed with distilled water, air dried and then oven dried at a temperature of $34^{\circ} \mathrm{C}$. The resulting orange peel was then grinded in a conventional grinding machine then sieved using vibrating sieve with mesh size $1000 \mu \mathrm{m}, 750 \mu \mathrm{m}$, $500 \mu \mathrm{m}, 350 \mu \mathrm{m}$ and the final particle size of $350 \mu \mathrm{m}$ was used as part of the reinforcement material.

\subsection{Sample Preparation}

Simple hand layup was adopted in the sample preparation process using a $25 \%$ glass fiber in a polyester resin matrix. Some quantity of unsaturated polyester was measured using a calibrated measuring cylinder. Cobalt naphthalene (accelerator) was first added to the measured polyester resin in drops and then in excess using a well calibrated syringe followed by methyl ethyl ketone peroxide. The resulting mixtures were then mechanically stirred for ten minutes to obtain a homogenous mixture. The resulting mixture was divided into six containers and different weight percent of orange peel particulates $(3 \mathrm{wt} . \%, 6 \mathrm{wt} . \%, 9 \mathrm{wt} . \%, 12 \mathrm{wt} . \%$, and $15 \mathrm{wt} . \%)$ was dispersed in each container and stirred thoroughly before setting.

Using an open mould of dimension $60 \mathrm{~cm} \times 12 \mathrm{~cm} \times 20 \mathrm{~cm}$, divided into six different compartments in accordance with the number of samples, lamination was done by placing the fiber mat in the mould and then saturated with the resulting mixture with the use of a hand brush. A sample containing only a fiber mat in a polyester resin matrix was prepared and used as a control sample. After solidification, the samples were removed from the mould and left for 7 days to cure in the air. The resulting samples were then fed into a pre-heated oven, and the oven was set to a temperature of $60^{\circ} \mathrm{C}$ for a period of $3 \mathrm{hrs}$ to post-cure the sample [17].

\section{Test Methods}

\subsection{Density}

The density of the samples was determined using Archimedes' principle. The samples were cut into regular shapes and the weighed as $\mathrm{m}$. A calibrated cylinder was filled with water and the level of water noted and recorded as $v 1$, while the sample was then immersed in the water and the rise in volume of water in the cylinder was noted and recorded as $v 2$.

The density of the sample was then determined using Equation 1.

Density $(\varrho)=\frac{m}{v 2-v 1}\left(\mathrm{~g} / \mathrm{cm}^{3}\right)$

\subsection{Water Absorption}

The water absorption tendencies of the samples were determined in accordance to ASTM D-570 [18]. Samples of suitable sizes for water absorption was cut, weighed dried and noted as $w \%$. The sample was left in the water for $24 \mathrm{hrs}$. The samples were then removed and then re-weighed as $w_{2}$. The percentage weight gained was calculated and recorded for each sample as the percentage of water absorbed. And this calculation was done using Equation 2.

Water absorption $=\frac{w 2-w 1}{w 1} \times 100$

\subsection{Tensile Test}

Edges of the samples were finished using grit paper. The tensile test was carried out according to ASTM D638 (165 x19) [19] and $5 \mathrm{~mm}$ thickness, at a crosshead speed of $50 \mathrm{~mm} / \mathrm{min}$. The machine is designed to stretch the specimen at a constant rate and it continuously and simultaneously measure the instantaneous 
applied load, and the resulting elongation using an extensometer. Two tensile test specimens with thickness $(\mathrm{t}) \mathrm{mm}$, length $(\mathrm{L}) \mathrm{mm}$, and width(b)mm, were cut for the tensile test. the tensile strength can be determined using.

$\sigma_{t}=\rho / A$

but $A=t * b * L$

$\sigma_{t}=\frac{\rho}{t * b * L}$

\subsection{Flexural Test}

Flexural test was carried out in a universal tensile testing machine using the three-point flexural testing method according to ASTM D-790 [20]. Test samples were cut to appropriate sizes and each sample was subjected to bending test with the aid of an improvised support and a centre point load until it breaks. At a load $\varrho(1000 \mathrm{kN})$ applied on the entire span $(\mathrm{L})$, the load acting on cross-sectional area $(\mathrm{A})$, then the flexural strength $\left(\sigma_{f}\right)$ was determined using [21].

$\sigma_{f}=\frac{3 F L}{2 A} \quad$ Where $A=w * t^{2}$

$w$ and $t$ and the width and thickness of specimen $(\mathrm{mm})$, respectively.

\subsection{Hardness Test}

Hardness test was carried out using the Rockwell hardness testing machine (Indentec universal hardness machine model 81875.5LKV frank well) using scale B. The indenter was $1 / 6$ inches steel ball and a minor load of $10 \mathrm{kgf}$ and a total load of $60 \mathrm{kgf}$ was used. The hardness value of the samples was read directly from the hardness testing machine.

\subsection{Impact Test}

Impact test was conducted with the aid of a PIT series Charpy impact testing machine with a pendulum of up to $150 \mathrm{~J}$, using a $2 \mathrm{~mm} \mathrm{~V}$-notched specimen. The dimension of the specimen is in accordance with ASTM D6110-18 [22]. The impact energy was obtained by recording the loss in energy of the pendulum after hitting the samples directly from the machine.

\section{Results and Discussion}

\subsection{Physical Properties}

The resulting physical properties of the composites depend on the nature of the reinforcement materials in terms of; orientations, loading condition, interfacial adhesion, voids and surface protection [23]. As shown in Table 1, the water absorption tendencies of the hybrid composite increase with increase in weight percent of the orange peel particulate while Table 2 also showed that the density of the composite sample increases with increase in percentage of particulate reinforcement.

Table 1: Water absorption tendencies of the composites

\begin{tabular}{|l|c|c|c|c|l|}
\hline S/N. & $\begin{array}{l}\text { wt\% of orange peel } \\
\text { particulate }\end{array}$ & $\begin{array}{l}\text { wt\% of samples before } \\
\text { soaking }\end{array}$ & $\begin{array}{l}\text { wt\% of samples } \\
\text { after soaking }\end{array}$ & $\begin{array}{l}\text { wt\% of water ab- } \\
\text { sorbed }\end{array}$ & $\begin{array}{l}\text { wt\% of Glass } \\
\text { Fiber }\end{array}$ \\
\hline 1 & 0 & 4.20 & 4.21 & 0.24 & 25.1 \\
\hline 2 & 3 & 4.26 & 4.29 & 0.70 & 25.1 \\
\hline 3 & 6 & 5.73 & 5.77 & 0.69 & 25.1 \\
\hline 4 & 9 & 3.01 & 3.05 & 1.19 & 25.1 \\
\hline 5 & 12 & 4.47 & 4.52 & 1.32 & 25.1 \\
\hline 6 & 15 & 4.49 & 4.67 & 1.96 & 25.1 \\
\hline
\end{tabular}


Mamman et al., Adv. J. Grad. Res.; Vol. 7, Issue 1, pp: 18-26, January 2020

Table 2: Effect of particulate reinforcement and glass fibers on the density of the composites

\begin{tabular}{|l|c|c|c|}
\hline S/N. & wt\% of orange peel particulate & Density of samples in $\mathrm{g} / \mathrm{cm}^{3}$ & wt\% of Glass Fiber \\
\hline 1 & 0 & 1.73 & 25.1 \\
\hline 2 & 3 & 1.82 & 25.1 \\
\hline 3 & 6 & 2.30 & 25.1 \\
\hline 4 & 9 & 2.40 & 25.1 \\
\hline 5 & 12 & 2.62 & 25.1 \\
\hline 6 & 15 & 2.78 & 25.1 \\
\hline
\end{tabular}

The observed continuous increase in water absorption from 0.24 to $1.96 \%$ with increase in particulate reinforcement was as a result of the hydrophilic nature of the particulate reinforcement. This phenomenon was also explained by Islam et al., [23], that natural fillers are composed of cellulose and when exposed to an aquatic environment tends to swell and absorb water. This might also impair the interfacial adhesion between the ply of the resulting composites thereby reducing the mechanical properties of the resulting composite and limiting their applications. Figure 1 is a plot of the physical properties of the composite samples versus the weight percentage of the particulate reinforcement and it can be seen that the physical properties increases all through as the percentage weight of the reinforcement increases. Ideally, the particulate reinforcement was supposed to reduce voids within the composite and limit the water uptake by the composite material but the hydrophilic nature of the particulate reinforcement accelerated the water uptake of the composite hence for the composite to be well suited for use in the marine industry, the particles should be carbonized or well treated smaller size particles should be used as this will reduced water intake and improve the mechanical properties of the composite.

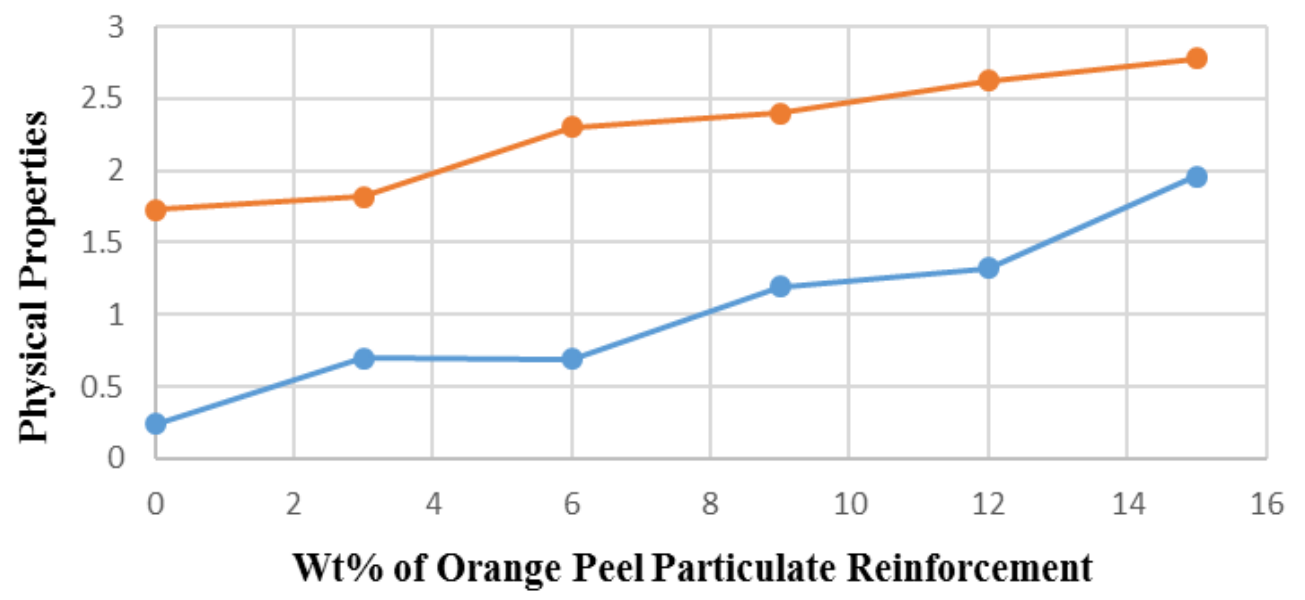

-Water absorbed $\quad-$ Density of the Samples

Figure 1: Graph of Physical Properties Versus Percentage weight of Particulate Reinforcement

From Figure 1, the density of the composite increases with increased percentage of particulate reinforcement from $1.73 \mathrm{~g} / \mathrm{cm}^{3}$ for the control sample to $2.78 \mathrm{~g} / \mathrm{cm}^{3}$ for the sample with about $15 \mathrm{wt}^{\%} \mathrm{p}$ particulate reinforcements. Such increase in density is not desirable for a composite material hence for the material to be suitable for the intended use, the orange peel particulate should be used in the form of a fly-ash as studies have shown that increase in fly-ash content of particulate reinforced composites reduced the density of the resulting composite and improve the thermal properties [24] [25].

\subsection{Mechanical Properties}

Table 3 shows the results of the tensile test for the six samples which include the control sample and the particulate reinforced samples. The tensile properties of the resulting composite samples were observed to be highest for the sample with highest percentage weight of particulate reinforcement with a value of 62.6 
Mechanical and Physical Properties of Polyester Reinforced Glass Fibre/Orange Peel Particulate Hybrid Composite

$\mathrm{MPa}$ and lowest for the control sample with 50.0 MPa. According to a Fourier Transform Infrared Spectroscopy (FTIR) report [26], orange peel particulates contains some compounds $\left(-\mathrm{OH}, \mathrm{CH}_{2}, \mathrm{CH}_{3}, \mathrm{Si}-\mathrm{O}-\mathrm{Si}\right.$, $\mathrm{C}=\mathrm{C}$ and $\mathrm{Si}=\mathrm{H})$ that contains double bonds and ties triple aromatic rings in the matrix of the resin matrix thereby increasing the interfacial adhesion between the matrix and reinforcement materials and increase the mechanical strength of the resulting composite material. Hence the tensile strength of the composite increase as the percentage weight of particulate reinforcement increases.

Table 3: Effect of particulate reinforcement and glass fibers on the tensile strength of the composite

\begin{tabular}{|l|c|c|c|c|l|l|}
\hline S/N & $\begin{array}{l}\text { wt\% of Or- } \\
\text { ange peel } \\
\text { particulates }\end{array}$ & $\begin{array}{l}\text { Width b } \\
(\mathrm{mm})\end{array}$ & $\begin{array}{l}\text { Thickness t } \\
\text { in }(\mathrm{mm})\end{array}$ & $\begin{array}{l}\text { Load, } \rho \text { in } \\
(\mathrm{N})\end{array}$ & $\begin{array}{l}\text { Tensile } \\
\text { strength in } \\
(\mathrm{MPa})\end{array}$ & $\begin{array}{l}\text { wt\% of } \\
\text { Glass Fiber }\end{array}$ \\
\hline 1 & 0 & 19 & 5.0 & 4753 & 50.0 & 25.1 \\
\hline 2 & 3 & 19 & 5.0 & 4829 & 50.8 & 25.1 \\
\hline 3 & 6 & 19 & 5.0 & 5127 & 53.9 & 25.1 \\
\hline 4 & 9 & 19 & 5.0 & 5331 & 56.1 & 25.1 \\
\hline 5 & 12 & 19 & 5.0 & 5660 & 59.6 & 25.1 \\
\hline 6 & 15 & 19 & 5.0 & 5947 & 62.6 & 25.1 \\
\hline
\end{tabular}

The hardness test values recorded from the Rockwell hardness tester are shown in Table 4 . It can be seen from that the hardness values increase from 28.6 HRB for the control sample to $40.8 \mathrm{HRB}$ with $15 \mathrm{wt}^{\%} \%$ of the particulate reinforcement.

Table 4: Effect of particulate reinforcement and glass fibers on the hardness of the composite

\begin{tabular}{|l|c|c|c|}
\hline No. & wt\% of Orange peel particulate & Hardness values (HRB) & wt\% of Glass Fiber \\
\hline 1 & 0 & 28.6 & 25.1 \\
\hline 2 & 3 & 30.1 & 25.1 \\
\hline 3 & 6 & 34.6 & 25.1 \\
\hline 4 & 9 & 36.5 & 25.1 \\
\hline 5 & 12 & 38.4 & 25.1 \\
\hline 6 & 15 & 40.8 & 25.1 \\
\hline
\end{tabular}

The observed increase in the hardness value as the particulate reinforcement increase was because the small voids available in the matrix has been filled up by the high concentration of the particulate reinforcement thereby resulting to an even distribution of the test load on both the fiber reinforcement and orange peel particulate and reducing the penetration of the indenter on the surfaces of the test samples this is in conformation with a study by [1].

Similarly, the impact energy of the composite samples increases with increasing percentage weight of the orange peel particulates. The highest impact energy of 7.4 Joules was recorded for the sample with $15 \mathrm{wt} \%$ of orange peel particulates while the lowest impact energy value was recorded for the control sample with $0 \mathrm{wt} \%$ of particulate reinforcement as shown in Table 5.

Table 5: Effect of particulate reinforcement and glass fibers on the impact strength of the composite

\begin{tabular}{|c|c|c|c|c|l|}
\hline S/N & $\begin{array}{l}\text { wt\% of Orange } \\
\text { peel particulate }\end{array}$ & $\begin{array}{l}\text { Impact energy } \\
(\mathrm{J}) .1^{\text {st }} \text { reading }\end{array}$ & $\begin{array}{l}\text { Impact energy } \\
(\mathrm{J}) .2^{\text {nd }} \text { reading }\end{array}$ & $\begin{array}{l}\text { Average Impact } \\
\text { energy }(\mathrm{J}) .\end{array}$ & $\begin{array}{l}\text { wt\% of Glass Fi- } \\
\text { ber }\end{array}$ \\
\hline 1 & 0 & 4.9 & 5.1 & 5.0 & 25.1 \\
\hline 2 & 3 & 5.3 & 5.4 & 5.4 & 25.1 \\
\hline 3 & 6 & 5.5 & 5.7 & 5.6 & 25.1 \\
\hline 4 & 9 & 6.0 & 6.2 & 6.1 & 25.1 \\
\hline 5 & 12 & 6.8 & 7.1 & 6.9 & 25.1 \\
\hline 6 & 15 & 7.5 & 7.3 & 7.4 & 25.1 \\
\hline
\end{tabular}

As depicted in Table 5, the observed increase in the value of impact energy as the percentage weight of the particulate reinforcement increase as a result of a better mechanical interlocking between the reinforcement 
Mamman et al., Adv. J. Grad. Res.; Vol. 7, Issue 1, pp: 18-26, January 2020

and the matrix material thereby causing a fracture of the fiber at the crack-plane with less fiber pull-out as reported by [27]. Table 6 . shows the flexural strength of the resulting composite samples together with the load applied, width, weight percent of particulate reinforcement and length of span.

Table 6: Effect of particulate reinforcement and glass fibers on the flexural strength of the composite

\begin{tabular}{|c|c|c|c|c|c|c|l|}
\hline S/N & $\begin{array}{l}\text { wt\% of orange } \\
\text { peel particulate }\end{array}$ & $\begin{array}{l}\text { Width } \\
\mathrm{B}(\mathrm{mm})\end{array}$ & $\begin{array}{l}\text { Support span L } \\
(\mathrm{mm})\end{array}$ & $\begin{array}{l}\text { Depth d } \\
(\mathrm{mm})\end{array}$ & $\begin{array}{l}\text { Load } \rho \\
(\mathrm{KN})\end{array}$ & $\begin{array}{l}\text { Flexural strength } \sigma_{\mathrm{p}} \\
(\mathrm{MPa})\end{array}$ & $\begin{array}{l}\text { wt\% of } \\
\text { Glass Fiber }\end{array}$ \\
\hline 1 & 0 & 25.0 & 80 & 10.0 & 3.1 & 74.0 & 25.1 \\
\hline 2 & 3 & 25.0 & 80 & 10.0 & 3.2 & 77.2 & 25.1 \\
\hline 3 & 6 & 25.0 & 80 & 10.0 & 5.2 & 79.6 & 25.1 \\
\hline 4 & 9 & 24.9 & 80 & 10.0 & 4.9 & 81.1 & 25.1 \\
\hline 5 & 12 & 25.0 & 80 & 10.0 & 5.6 & 83.7 & 25.1 \\
\hline 6 & 15 & 25.0 & 80 & 10.0 & 3.6 & 85.2 & 25.1 \\
\hline
\end{tabular}

The flexural strength of the composite increases from 74.0MPa for the control sample to 85.2MPa for the sample with $14 \mathrm{w} \%$ reinforcement. It can be seen that the flexural strength increases with increase in percentage weight of the of the orange peel particulates. As the particulate reinforcement increases and also leveraging on the fiber matrix interaction will lead to an increased transfer of stress from the fragile matrix to the glass fibers and orange peel particulate which will in-turn increase the flexural strength of the hybrid composite [27].

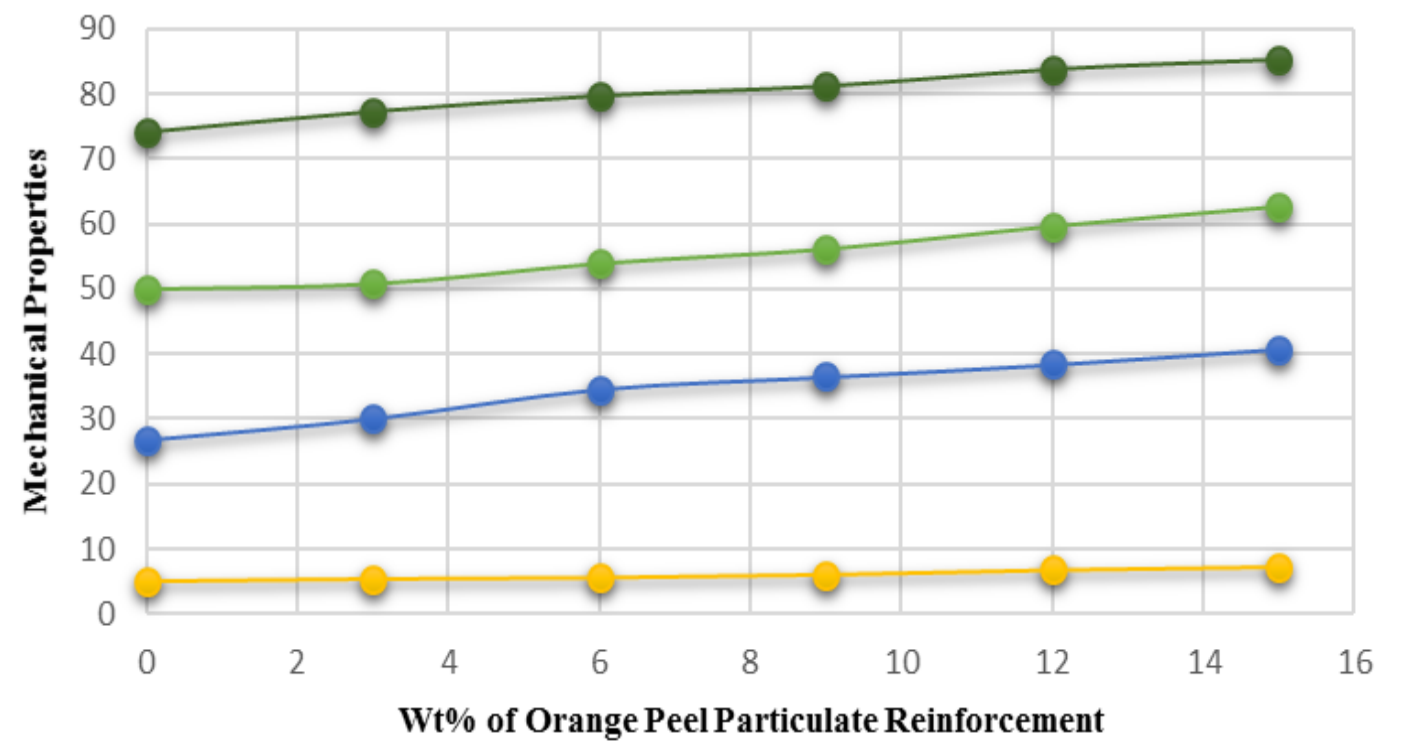

$\multimap-$ Tensile (Mpa) - $\longrightarrow$ Hardness (HRB) $\multimap$ Impact (J) $\longrightarrow$ Flexural (Mpa)

Figure 2: Mechanical Properties of Particulate reinforced hybrid composite versus Percentage weight of particulate reinforcement

A plot of the mechanical properties of the resulting composite samples versus the percentage weight of the particulate reinforcement as shown in Figure 2, indicates a continuous increase in mechanical properties of the composite materials with increase in percentage weight of the orange peel particulates.

\section{Conclusions}

In this study, orange peel has been shown to improve the mechanical properties of polyester reinforced glass fibers with $15 \mathrm{w} \%$ particulate reinforced composite sample exhibiting the best mechanical properties all through with a tensile strength of $62.6 \mathrm{MPa}$, hardness value of $40.8 \mathrm{HRB}$, impact energy of 7.5 Joules and flexural strength of $85.2 \mathrm{MPa}$. The study also showed that the water absorption tendencies of the composite increases with increase in percentage weight of the particulate reinforcement which was due to 
the hydrophilic nature of the orange peels and it was suggested that using it in the form of fly-ash or proper treatment of smaller sieve size sample will reduce the water absorption tendencies of the resulting composite samples. Thus, orange peel is a good reinforcing filler in polymer composites. This will also serve as a means of reducing environmental pollution arising from the deposition in the environment.

\section{Declarations}

\subsection{Study Limitation}

This study did no carry out scanning election microscopy (SEM), chemical characterization and Fourier Transform Infrared Spectroscopy. This was due to the unavailability of the facilities at the metallurgical workshop, Ahmadu Bello University Zaria, Nigeria.

\subsection{Competing Interests}

The authors declared that no conflict of interest exist in the publication of this work

\section{How to Cite this Article:}

R. Mamman and A. Ramalan, "Mechanical and Physical Properties of Polyester Reinforced Glass Fibre/Orange Peel Particulate Hybrid Composite”, Adv. J. Grad. Res., vol. 7, no. 1, pp. 18-26, Oct. 2019. doi: 10.21467/ajgr.7.1.18-26

\section{References}

[1]. M. A. Usman, I. Momohjimoh, A. SB. Gimba, (2016); "Effect of Groundnut Shell Powder on the Mechanical Properties of Recycled Polyethylene and Its Biodegradability,". Journal of Minerals and Material Characterization and Engineering, Vol. 4, pp. 228-240, 2016.

[2]. L. Lin, and A. K. Schlarb, "The Roles of Rigid Particles on the Friction and Wear Behaviour of Short Carbon Fiber Reinforced PBT Hybrid Materials in the Absence of Solid Lubricants," Tribology International, Vol. 119, pp. 404-410, 2018.

[3]. D. Amrishraj and T. Senthilvelan, "Development of wear mechanism maps for Acrylonitrile Butadiene Styrene (ABS) hybrid composites reinforced with nano Zirconia and PTFE under dry sliding condition,”. Journal of Tribology, Vol. 141, pp. 021602-021614, 2019.

[4]. N. Verma, and S. C. Vettivel, "Characterization and experimental analysis of boron carbide and rice husk ash reinforced AA7075 aluminium alloy hybrid composite," Journal of Alloys and Compounds, Vol. 741, pp. 981-998, 2018.

[5] Y. Junjie, C. Chu, Z. Zhai, Y. Wang, B. Shi and Y. Qiu, "The interphase influence on the particle-reinforced composite with periodic particle configuration," Journal of applied science, Vol. 7, pp. 102, 2017.

[6]. S. Dixit, R. Goel, A. Dubey, P. R. Shivhare and T. Bhalavi "Natural Fibre Reinforced Polymer Composite Materials - A Review," Polymers from Renewable Resources, Vol. 8, No. 2, pp. 71-78, 2017.

[7]. M. W. Tham, MR. N. Fazita, HPS. A. Khalil, N. Z. M. Zuhudi, M. Jaafar, S. Rizal, and Mk. M. Haafiz, "Tensile properties prediction of natural fibre composites using rule of mixtures: A review," Journal of Reinforced of Plastics and Composites, Vol. 38, No. 5, pp. 211-248, 2018.

[8]. Z. Luo, X. Li, J. Shang, H. Zhu and D. Fang, "Modified rule of mixtures and Halpin-Tsai model for prediction of tensile strength of micron-sized reinforced composites and Young's modulus of multiscale reinforced composites for direct extrusion fabrication," Journal of Advances in Mechanical Engineering, Vol. 10, No. 7, pp. 1-10, 2018.

[9]. M. Kumar, R. N. Rajini, K. Mayandi, S. Siengchin, "Thermal Performance of Acrylonitrile Butadiene Styrene (ABS) Copolymer Blended with PTFE Particle/Polymer Composite,” Materials Science Forum, Vol. 969, pp. 444-450, 2018.

[10]. O. Nabinejad, D. Sujan, M. E. Rahman, W. Y. H. Liew, and I. J. Davies, "Hybrid Composite Using Natural Filler and Multi-Walled Carbon Nanotubes (MWCNTs)," Applied Composite Materials, Vol. 25, No. 6, pp. 1323-1337, 2017.

[11]. X. C. Zhang, F. Scarpa, R. McHale, and H. X. Peng, "Poly (methyl methacrylate)-decorated single wall carbon nanotube/epoxy nanocomposites with re-agglomeration networks: rheology and viscoelastic damping performance,". Polymer Journal. Vol. 87, pp. 236-245, 2016.

[12]. T. Uygunoğlu, W. Brostow, and I. Gunes. "Wear and friction of composites of an epoxy with boron containing wastes," Polimeros, Vol. 25, No 3, pp. 71-276, 2016.

[13]. M. V. FonsecaFerreira, A. C. CerqueiraNeves, C. G. deOliveira, F. P. DuarteLopes, F. MuylaertMargem, C. M. FontesVieira and S. NevesMonteiro. "Thermogravimetric characterization of polyester matrix composites reinforced with eucalyptus fibers," Journal of Materials Research and Technology, Vol. 6, No. 4, pp. 396-400, 2017.

[14]. R. Morgan, R. Jones, O. E. O. McGhee, S. L. Marshall, S. M. Hart, J. M. Urueña, S. R. Niemi, A. A. Pitenis and K. D. Schulze, “The Role of Microstructure in Ultralow Wear Fluoropolymer Composites," Journal of Tribology Transactions, Vol. 62, No. 1, pp. 135143, 2018

[15]. Q. Yuan, C. Wenhan, W. Honggang, R. Junfang and G. Gui, "Tribological Behavior of PTFE Composites Filled with PEEK and Nano- $\mathrm{Al}_{2} \mathrm{O}_{3}$, , Journal of Tribology Transactions, Vol. 61, No. 4, pp. 697-704, 2018.

[16]. I. C. Olife, O. A. Ibeagha, and A. P. Onwualu, "Citrus Fruits Value Chain Development in Nigeria," Journal of Biology, Agriculture and Healthcare, Vol. 5, No. 4, pp. 36-47, 2015.

[17]. Ç. Uzay, M. H. Boztepe, M. Bayramoglu and N. Geren, "Effect of post-curing heat treatment on mechanical properties of fiber reinforced polymer (FRP) composites," Material prufung, Vol. 59, No. 4, pp. 366-372, 2017. 
Mamman et al., Adv. J. Grad. Res.; Vol. 7, Issue 1, pp: 18-26, January 2020

[18]. ASTM D570-98, Standard Test Method for Water Absorption of Plastics, ASTM International, West Conshohocken, PA, 2018.

[19]. ASTM D638-14, Standard Test Method for Tensile Properties of Plastics, ASTM International, West Conshohocken, PA, 2014.

[20]. ASTM D790-17, Standard Test Methods for Flexural Properties of Unreinforced and Reinforced Plastics and Electrical Insulating Materials, ASTM International, West Conshohocken, PA, 2017.

[21]. RS. Khurmi and JK. Gupta. A Textbook of Machine Design. Eurasia Publishing House (PVT), New Delhi, India, 2005.

[22]. ASTM D6110-18, Standard Test Method for Determining the Charpy Impact Resistance of Notched Specimens of Plastics, ASTM International, West Conshohocken, PA, 2018.

[23]. M. R. Islam, A. Gupta, M. Rivai, M.D.H. Beg, and M. F. Mina, "Effects of Fiber-Surface Treatment on the Properties of Hybrid Composites Prepared from Oil Palm Empty Fruit Bunch Fibers, Glass Fibers, and Recycled Polypropylene," Journal of Applied Polymer Science, Vol. 133, No. 11, pp. 1-10.

[24]. P. Viswakarma, S. Soni, and P. M. Mishra, "An Effect of Reinforcement and Heat Treatment On Aa7075 Metal Matrix Composite A Review," International Journal of Mechanical and Production Engineering Research and Development, Vol. 8, No. 6, pp. 275288, 2018.

[25]. I. Momohjimoh, S. Nouari, M. A. Hussein, T. Laoui, N. Al-Aqeeli, "Thermal Behavior of Spark Plasma Sintered Alumina-Based Nanocomposites", Arabian Journal for Science and Engineering, Vol. 44, No. 6, pp. 6013-6028, 2019.

[26]. A. I. Al-Mosawi, S. A. Abdulsada, C. Kónya, G. Szemere "Orange peel waste as a reinforcing material for plasticised PVC," Grant Journal, Vol. 6, No. 2, pp. 88-91, 2017.

[27]. J. Somashekhara, B. Ramesh, V. Belagavi and H. Madhu, "Investigation and Study of Mechanical Properties of Areca Shell Fiber and Palm Powder Natural Composites," IOSR Journal of Mechanical and Civil Engineering, Vol. 15, No. 6, pp. 62-73, 2018.

\section{Publish your books with AIJR publisher-}

$\checkmark$ Publish with ISBN and DOI.

$\checkmark$ Publish Thesis/Dissertation as Monograph.

$\checkmark$ Publish Book Monograph.

$\checkmark$ Publish Edited Volume/ Book.

$\checkmark$ Publish Conference Proceedings

Retain full copyright of your books.

Submit your manuscript at books.aijr.org
Publish your research article in AIJR journals-

$\checkmark$ Online Submission and Tracking

$\checkmark$ Peer-Reviewed

$\checkmark$ Rapid decision

$\checkmark$ Immediate Publication after acceptance

$\checkmark$ Articles freely available online

Retain full copyright of your article.

Submit your article at journals.aijr.in 